\title{
ASPECTOS TERMINOLÓGICOS EN TRADUCCIÓN CIENTÍFICA ESPAÑOL-FRANCÉS. UN CASO PRÁCTICO \\ $M^{a}$ Isabel Martinez Robledo \\ Universidad de Granada
}

\begin{abstract}
The objective of this article is to introduce a standard when dealing with technical translation through the examination of a case study taken from a bilingual terminological project on French-Spanish Scientific Translation. To this end, this article will study the different stages which should be followed when translating a scientific text from the stage of documentation and term management, which includes a compilation of terminology records, a bilingual glossary, a conceptual structure and an index of terms, up to that of translation, with particular emphasis on the issue of translation.
\end{abstract}

KEYWORDS: terminology, technical translation, French, Spanish, viticulture.

\section{RESUMEN}

El objetivo de este artículo es establecer unas pautas a la hora de abordar la Traducción Especializada, mediante el análisis de un caso práctico extraído de un proyecto terminológico bilingüe sobre Traducción Científica Español-Francés. Para ello, se hará un estudio de las distintas fases que se deben seguir a la hora de traducir un texto científico, desde la fase de documentación y gestión terminológica (que engloba la elaboración de fichas terminológicas, el glosario bilingüe, la estructura conceptual y el índice de términos) hasta la fase de traducción (haciendo especial hincapié en la problemática de la traducción).

PALABRAS CLAVE: terminología, traducción especializada, español, francés, viticultura.

\section{INTRODUCCIÓN}

El caso práctico que se va a exponer está basado en un proyecto terminológico puntual bilingüe español-francés sobre Patología y Parasitología de la vid realizado conjuntamente entre la Universidad de Granada y la 
Universidad de Córdoba y publicado en 19981. La Viticultura es un campo de especialidad que posee una larga tradición, sobre todo en España y Francia ya que, debido a su clima, son dos de los grandes países del Mediterráneo cultivadores de la vid y productores de algunos de los vinos de más reconocido prestigio en el mundo. Por lo tanto, la traducción entre el par de lenguas español-francés y francés-español en el área de la Viticultura es una de las más demandadas en el mercado de la Traducción Especializada. Sin embargo, debido a la amplitud de este campo de especialidad, vamos a delimitar el tema y nos vamos a centrar exclusivamente en la problemática de la traducción de los términos relacionados con las enfermedades de la vid, es decir, la Patología y la Parasitología de la vid.

\section{FASE DE DOCUMENTACIÓN Y GESTIÓN TERMINOLÓGICA}

A la hora de abordar este tema, como en el caso de cualquier otro campo de especialidad, es necesario realizar una intensiva labor de documentación para introducirse en el campo de especialidad y adquirir unos conocimientos terminológicos aceptables. Las principales dificultades que surgen en esta etapa de documentación son la escasez de documentos existentes en ambas lenguas y la necesidad de elaborar un proyecto de gestión terminológica que podría clasificarse como un trabajo puntual bilingüe ya que, dentro de un subdominio delimitado, recoge un número determinado de términos en dos idiomas, en este caso el español y el francés. Teniendo en cuenta el tipo de usuario, su función principal es la descriptiva ya que, a través de la definición de los conceptos y de la estructuración de los mismos, el destinatario puede tener una visión general del campo tratado.

La elaboración del proyecto terminológico consta de las siguientes fases:

1. Fase de documentación: selección de documentos que recojan información sobre el tema. Para ello, es necesario realizar una búsqueda exhaustiva en diferentes fuentes, como pueden ser bibliotecas de distintas universidades, Internet y bases de datos internacionales. Pero, fundamentalmente, es imprescindible contactar con varios expertos en la materia, tanto para conseguir material especializado de difícil acceso, como para resolver las dudas terminológicas que puedan surgir.

1 Ma Isabel Martínez Robledo et al., Patología y Parasitología de la Vid (Proyecto terminológico puntual bilingüe Español-Francés), Departamento de Bromatología y Tecnología de los Alimentos, Universidad de Córdoba, Córdoba, 1998, 41 páginas. ISBN: 84-605-8130-6. 
2. Fase de planificación: una vez conseguido el material, es necesario seleccionar y dividir el tema en subapartados, atendiendo al volumen global del corpus de vaciado.

3. Fase de elaboración: partiendo de una lectura global del material, y habiendo elaborado un sistema conceptual único, se procede a la elaboración de las fichas terminológicas, del glosario bilingüe y del índice de términos.

4. Fase de resolución de los casos problemáticos: resolución de los problemas surgidos en la fase de elaboración, a través de la consulta a diferentes expertos.

5. Fase de edición: edición y conclusión del proyecto terminológico, de forma que se adapte de forma adecuada a la fase siguiente: la fase de traducción.

\section{FASE DE CREACIÓN DEL PROYECTO TERMINOLÓGICO}

A continuación, vamos a mostrar un ejemplo de la creación del proyecto terminológico sobre Patología y Parasitología de la Vid, que se divide en las siguientes secciones:

\section{ESTRUCTURACIÓN Y DIVISIÓN DEL TEMA}

El trabajo se divide en dos grandes bloques: Patología (enfermedades) y Parasitología (plagas) de la vid. Atendiendo a esta división, los términos que se recogen en este campo conceptual bilingüe se encuentran organizados según los siguientes criterios de clasificación:

1. PATOLOGÍA.

a) Enfermedades criptogámicas (HONGOS).

Enfermedades (vid y fruto).

Podredumbres (fruto).

Podredumbres radiculares (raíz).

b) Enfermedades BACTERIANAS.

c) Enfermedades VIROSAS.

d) Enfermedades SIMILARES A LAS VIROSAS.

e) Accidentes METEOROLÓGICOS (daños por el clima). 
f) Enfermedades FISIOLÓGICAS.

2. PARASITOLOGÍA.

a) Insectos que atacan a las HOJAS.

b) Insectos que atacan a las FLORES y a los FRUTOS.

c) Insectos que atacan a las YEMAS y a los BROTES.

d) Insectos que atacan a las PARTES PERMANENTES de la vid.

e) Insectos que atacan a las RAÍCES.

f) Insectos que atacan a las PASAS.

g) Plagas producidas por VERTEBRADOS y GASTERÓPODOS.

\section{ELABORACIÓN DE LAS FICHAS TERMINOLÓGICAS}

Este artículo está basado en un proyecto terminológico que consta de 20 fichas terminológicas, a modo de ejemplo ilustrativo. En cuanto a las fichas, las 15 primeras (enumeradas del 01 al 15) contienen términos que pertenecen a la Patología y muestran las enfermedades más importantes de la vid, ya sea por los daños que provocan en ésta, ya sea por su reconocimiento internacional. Las últimas 5 fichas (enumeradas del 16 al 20) contienen, cada una de ellas, un término relativo a una plaga de la vid y han sido elegidas principalmente por el rastro tan característico y peculiar que van dejando en las hojas a las que atacan, facilitando que éstas sean reconocidas incluso por aquellas personas que posean un conocimiento restringido de la materia.

Cada ficha bilingüe consta de las siguientes partes: el $n^{\circ}$ de la ficha, el nombre del trabajo al que pertenece, el dominio y subdominio temático del mismo, el término, su categoría gramatical, los idiomas entre los que se establece la equivalencia, los posibles sinónimos del término, su definición y contexto, la nota técnica y las referencias bibliográficas. En el caso de la Parasitología, se incluye una ilustración del parásito.

\section{EJEMPLO DE FICHA TERMINOLÓGICA}

\begin{tabular}{|c|c|c|c|c|}
\hline $\mathbf{N}^{\circ}:$ & 01 & \multicolumn{3}{|c|}{$\begin{array}{l}\text { NOMBRE PROYECTO: } \\
\text { PATOLOGÍA Y PARASITOLOGÍA DE LA VID }\end{array}$} \\
\hline IDIOMA: & \multicolumn{4}{|l|}{ ES } \\
\hline DOM: & Viticultura & SDOM: & Patología/Parasitología d & la vid \\
\hline TER: & \multicolumn{3}{|l|}{ OIDIO } & $\mathrm{N}$ \\
\hline SIN: & \multicolumn{4}{|c|}{ Ö̈dium, Mildio polvoriento } \\
\hline
\end{tabular}


ENTREC ULTURAS Número 1. ISSN: 1989-5097. Fecha de public ación: 27-03-2009

\begin{tabular}{|c|c|c|c|}
\hline DF: & \multicolumn{3}{|c|}{$\begin{array}{l}\text { Enfermedad criptogámica de la vid producida por un hongo, Uncinula } \\
\text { necator, que ataca a todos los órganos verdes produciendo un } \\
\text { crecimiento translúcido en forma de telaraña que sale radialmente del } \\
\text { manchón donde la espora empieza a crecer y que, debido al gran } \\
\text { número de esporas, tiene una apariencia polvorienta. }\end{array}$} \\
\hline CO: & \multicolumn{3}{|c|}{$\begin{array}{l}\text { "El Oidio es un hongo microscópico que se desarrolla en la superficie } \\
\text { de los órganos verdes, mientras que el Mildiu se desarrolla en el } \\
\text { interior." }\end{array}$} \\
\hline NT: & \multicolumn{3}{|c|}{$\begin{array}{l}\text { En español puede aparecer como "Oidio" u "Ö̈dium". } \\
\text { En California se le conoce como "Mildio". } \\
\text { En México se denomina "Cenicilla polvorienta". } \\
\text { Las manchas del Oidio se parecen a las del Mildio, por lo que a veces } \\
\text { las dos enfermedades suelen confundirse. }\end{array}$} \\
\hline RF: & \multicolumn{3}{|c|}{$\begin{array}{l}\text { M. Channet / A. Reynier (traducción de F. Gil-Albert Velarde), Manual } \\
\text { de Viticultura, } 1974 \text { (TER) (CO: pp. 206-207). } \\
\text { Según A. J. Winkler (traducción de Guillermo Fernández de Lara), } \\
\text { Viticultura, } 1980 \text { (SIN) (DF) (NT). }\end{array}$} \\
\hline \multicolumn{4}{|c|}{ QUIVALENTE: $\quad$ FR } \\
\hline DOM: & Viticulture & SDOM: & $\begin{array}{l}\text { Pathologie/Parasitologie de la } \\
\text { vigne }\end{array}$ \\
\hline TER: & \multirow{2}{*}{\multicolumn{3}{|c|}{ OÏDIUM }} \\
\hline SIN: & & & \\
\hline DF: & \multicolumn{3}{|c|}{$\begin{array}{l}\text { Maladie cryptogamique due à un champignon, Uncinula necator, } \\
\text { caractérisée par une poussière ténue de couleur grise qui forme des } \\
\text { plages d'étendue variable, aux contours peu nets, sur tous les organes } \\
\text { herbacés qui sont affectés dans leur taille, leur forme et leur } \\
\text { disposition. }\end{array}$} \\
\hline CO: & \multicolumn{3}{|c|}{$\begin{array}{l}\text { "Au vignoble, les produits cupriques agissent sur l'oïdium au cours des } \\
\text { pluies, plus fortement dans les régions pluvieuses en été et d'autant } \\
\text { plus intensément que les applications sont plus nombreuses." }\end{array}$} \\
\hline NT: & \multicolumn{3}{|c|}{ La lésion de l'Ö̈dium est parfois confondue avec celle du Mildiou. } \\
\hline RF: & \multicolumn{3}{|c|}{$\begin{array}{l}\text { D'après Jean Brahnas, Viticulture, } 1974 \text { (TER) (DF) (CO : page 755) } \\
\text { (NT). }\end{array}$} \\
\hline
\end{tabular}

\section{GLOSARIO BILINGÜE DE TÉRMINOS}

El glosario bilingüe está formado por los 20 términos que figuran a su vez en las fichas terminológicas, ordenados alfabéticamente, en primer lugar con la entrada en español y, posteriormente, con la entrada en francés. 
ENTREC ULTURAS Número 1. ISSN: 1989-5097. Fecha de publicación: 27-03-2009

\section{Ordenación por idioma español:}

\begin{tabular}{|l|l|}
\hline Amarilleamientos de la vid & Jaunissement de la vigne \\
\hline Apoplejía parasitaria & Apoplexie \\
\hline Black-Rot & Black-Rot \\
\hline Bromius obscurus & Bromius obscurus \\
\hline Byctiscus betulae L. & Byctiscus betulae L. \\
\hline Celerio lineata Fabr. & Celerio lineata Fabr. \\
\hline Clorosis caliza & Chlorose \\
\hline Corrimiento de la vid & Coulure \\
\hline Desecación del raquis o raspón & Asphyxie radiculaire \\
\hline Encrespamiento de la hoja & Court-noué \\
\hline Enfermedad de Pierce & Maladie de Pierce \\
\hline Enrojecimiento & Rougeau \\
\hline Enrollamiento de la hoja & Enroulement \\
\hline Eriophes vitis Pgst. & Eriophes vitis Pgst. \\
\hline Flavescencia dorada & Flavescence dorée \\
\hline Mildiu & Mildiou \\
\hline Oidio & Öidium \\
\hline Podredumbre Ozonium de la raíz & Ozonium Root Rot \\
\hline Tetranychus urticae Koch & Tetranychus urticae Koch \\
\hline Tilosis & Thyllose \\
\hline &
\end{tabular}

\section{Ordenación por idioma francés:}

\begin{tabular}{|l|l|}
\hline Apoplexie & Apoplejía parasitaria \\
\hline Asphyxie radiculaire & Desecación del raquis o raspón \\
\hline Black-Rot & Black-Rot \\
\hline Bromius obscurus & Bromius obscurus \\
\hline Byctiscus betulae L. & Byctiscus betulae L. \\
\hline Celerio lineata Fabr. & Celerio lineata Fabr. \\
\hline Chlorose & Clorosis caliza \\
\hline Coulure & Corrimiento de la vid \\
\hline Court-noué & Encrespamiento de la hoja \\
\hline Enroulement & Enrollamiento de la hoja \\
\hline Eriophes vitis Pgst. & Eriophes vitis Pgst. \\
\hline Flavescence dorée & Flavescencia dorada \\
\hline Jaunissement de la vigne & Amarilleamientos de la vid \\
\hline Maladie de Pierce & Enfermedad de Pierce \\
\hline Mildiou & Mildiu \\
\hline
\end{tabular}


ENTRECULTURAS Número 1. ISSN: 1989-5097. Fecha de publicación: 27-03-2009

\begin{tabular}{|l|l|}
\hline Ö̈dium & Oidio \\
\hline Ozonium Root Rot & Podredumbre Ozonium de la raíz \\
\hline Rougeau & Enrojecimiento \\
\hline Tetranychus urticae Koch & Tetranychus urticae Koch \\
\hline Thyllose & Tilosis \\
\hline
\end{tabular}

\section{ESTRUCTURA CONCEPTUAL}

Cada uno de estos términos encuentra su equivalente en francés. En el caso de la Parasitología consiste en la denominación científica, y por lo tanto universal, de cada tipo de plaga, así como de cualquier otra denominación por la que sea más popularmente conocida.

Los términos que aparecen en negrita son aquellos que se encuentran recogidos tanto en el glosario bilingüe como en las fichas terminológicas.

\begin{tabular}{|c|c|}
\hline 1. PATOLOGÍA. & 1. PATHOLOGIE. \\
\hline $\begin{array}{l}\text { 1.1. ENFERMEDADES } \\
\text { CRIPTOGÁMICAS. }\end{array}$ & 1.1. MALADIES CRYPTOGAMIQUES. \\
\hline $\begin{array}{l}\text { 1.1.1. ENFERMEDADES (VID Y } \\
\text { FRUTO). }\end{array}$ & $\begin{array}{l}\text { 1.1.1. MALADIES (RAMEAUX ET } \\
\text { FRUIT). }\end{array}$ \\
\hline 1.1.1.1. Mildiu. & 1.1.1.1. Mildiou. \\
\hline 1.1.1.2. Oidio. & 1.1.1.2. Ö̈dium. \\
\hline 1.1.1.3. Black-Rot. & 1.1.1.3. Black-Rot. \\
\hline 1.1.1.4. Antracnosis. & 1.1.1.4. Anthracnose maculée. \\
\hline 1.1.1.5. Excoriosis. & 1.1.1.5. Excoriose. \\
\hline 1.1.1.6. Apoplejía parasitaria. & 1.1.1.6. Apoplexie. \\
\hline 1.1.1.7. Brenner. & 1.1.1.7. Rougeot parasite. \\
\hline $\begin{array}{l}\text { 1.1.1.8. Mancha foliar por } \\
\text { Septoria. }\end{array}$ & 1.1.1.8. Mélanose. \\
\hline $\begin{array}{l}\text { 1.1.1.9. Mancha foliar por } \\
\text { Cercospora. }\end{array}$ & 1.1.1.9. Cercosporiose. \\
\hline 1.1.1.10. Roya. & 1.1.1.10. Rouille de la vigne. \\
\hline 1.1.1.11. Eutipiosis. & 1.1.1.11. Eutypiose. \\
\hline 1.1.2. PODREDUMBRES (FRUTO). & 1.1.2. POURRITURES (FRUIT). \\
\hline $\begin{array}{l}\text { 1.1.2.1. Podredumbre de moho } \\
\text { azul. }\end{array}$ & 1.1.2.1. Pourriture amère. \\
\hline $\begin{array}{l}\text { 1.1.2.2. Podredumbre de moho } \\
\text { negro. }\end{array}$ & 1.1.2.2. Pourriture noire. \\
\hline 1.1.2.3. Podredumbre Rhizopus. & 1.1.2.3. Pourriture à Rhizopus. \\
\hline
\end{tabular}


ENTRECULTURAS Número 1. ISSN: 1989-5097. Fec ha de publica ción: 27-03-2009

\begin{tabular}{|c|c|}
\hline 1.1.2.4. Podredumbre gris. & 1.1.2.4. Pourriture grise. \\
\hline $\begin{array}{l}\text { 1.1.2.5. Tizón apical de } \\
\text { sarmientos. }\end{array}$ & 1.1.2.5. Diplodia Dieback. \\
\hline $\begin{array}{l}\text { 1.1.2.6. Podredumbre } \\
\text { Cladosporium. }\end{array}$ & 1.1.2.6. Cladosporiose. \\
\hline 1.1.2.7. Podredumbre alternaria. & 1.1.2.7. Alternariose. \\
\hline $\begin{array}{l}\text { 1.1.2.8. Podredumbre madura y } \\
\text { amarga. }\end{array}$ & 1.1.2.8. Bitter Rot. \\
\hline 1.1.2.9. Podredumbre blanca. & 1.1.2.9. Rot blanc. \\
\hline $\begin{array}{l}\text { 1.1.3. PODREDUMBRES } \\
\text { RADICULARES (RAÍZ). }\end{array}$ & 1.1.3. POURRIDIÉS (RACINE). \\
\hline $\begin{array}{l}\text { 1.1.3.1. Podredumbre de la raíz } \\
\text { armillaria. }\end{array}$ & 1.1.3.1. Pourridié agaric. \\
\hline $\begin{array}{l}\text { 1.1.3.2. Podredumbre Ozonium } \\
\text { de la raíz. }\end{array}$ & 1.1.3.2. Ozonium Root Rot. \\
\hline $\begin{array}{l}\text { 1.1.3.3. Podredumbre } \\
\text { dematophora de la raíz. }\end{array}$ & 1.1.3.3. Pourridié laineux. \\
\hline $\begin{array}{l}\text { 1.1.3.4. Pudrición de raíces por } \\
\text { Roesleria. }\end{array}$ & 1.1.3.4. Pourridié morille. \\
\hline 1.1.3.5. Pudrición del collar. & 1.1.3.5. Pourriture du collet. \\
\hline $\begin{array}{l}\text { 1.2. ENFERMEDADES } \\
\text { BACTERIANAS. }\end{array}$ & 1.2. MALADIES BACTÉRIENNES. \\
\hline 1.2.1. Tizón. & 1.2.1. Nécrose bactérienne. \\
\hline 1.2.2. Nudo negro. & 1.2.2. Broussin parasite. \\
\hline 1.3. ENFERMEDADES VIROSAS. & 1.3. MALADIES À VIRUS. \\
\hline 1.3.1. Enfermedad de Pierce. & 1.3.1. Maladie de Pierce. \\
\hline 1.3.2. Flavescencia dorada. & 1.3.2. Flavescence dorée. \\
\hline 1.3.3. Encrespamiento de la hoja. & 1.3.3. Court-noué. \\
\hline 1.3.4. Amarilleamientos de la vid. & 1.3.4. Panachure. \\
\hline 1.3.5. Enrollamiento de la hoja. & 1.3.5. Enroulement. \\
\hline 1.3.6. Mosaico asteroide. & 1.3.6. Mosaïque étoilée. \\
\hline 1.3.7. Corteza corchosa. & 1.3.7. Écorce liégeuse. \\
\hline 1.3.8. Mosaico amarillo. & 1.3.8. Yellow mosaic. \\
\hline 1.3.9. Listado o franjeado de las venas. & \\
\hline 1.3.10. Vena amarilla. & \\
\hline $\begin{array}{l}\text { 1.4. ENFERMEDADES SIMILARES A } \\
\text { LAS VIROSAS. }\end{array}$ & \\
\hline 1.4.1. Excrecencia. & \\
\hline 1.4.2. Brote ahusado. & \\
\hline $\begin{array}{l}\text { 1.5. ACCIDENTES } \\
\text { METEOROLÓGICOS. }\end{array}$ & 1.4. ACCIDENTS CLIMATIQUES. \\
\hline
\end{tabular}


ENTREC ULTURAS Número 1. ISSN: 1989-5097. Fecha de publicación: 27-03-2009

\begin{tabular}{|c|c|}
\hline 1.5.1. Heladas. & 1.4.1. Gelées. \\
\hline 1.5.1.1. Heladas de otoño. & 1.4.1.1. Gelées d'automne. \\
\hline 1.5.1.2. Heladas de invierno. & 1.4.1.2. Gelées d’hiver. \\
\hline 1.5.1.3. Heladas de primavera. & 1.4.1.3. Gelées de printemps. \\
\hline 1.5.2. Escaldado. & 1.4.2. Échaudage. \\
\hline 1.5.3. Vientos. & 1.4.3. Vents. \\
\hline 1.5.3.1. Vientos salinos. & 1.4.3.1. Folletage. \\
\hline 1.5.3.2. Vientos cálidos. & 1.4.3.2. Vents chauds. \\
\hline 1.5.3.3. Vientos húmedos. & \\
\hline 1.5.4. Daños por rayos. & 1.4.4. Foudre. \\
\hline 1.5.5. Granizo y pedrisco. & 1.4.5. Grêle. \\
\hline $\begin{array}{l}\text { 1.6. ENFERMEDADES } \\
\text { FISIOLÓGICAS. }\end{array}$ & 1.5. MALADIES PHYSIOLOGIQUES. \\
\hline 1.6.1. Corrimiento de la vid. & 1.5.1. Coulure. \\
\hline 1.6.2. Clorosis caliza. & 1.5.2. Chlorose. \\
\hline 1.6.3. Parpadeado. & 1.5.3. Flavescence. \\
\hline 1.6.4. Tilosis. & 1.5.4. Thyllose. \\
\hline 1.6.5. Enrojecimiento. & 1.5.5. Rougeau. \\
\hline 1.6.6. Agua del suelo. & 1.5.6. L'eau du sol. \\
\hline 1.6.6.1. Exceso. & 1.5.6.1. Excès. \\
\hline 1.6.6.2. Falta. & 1.5.6.2. Séchèresse. \\
\hline 1.6.7. Carencia o exceso de minerales. & $\begin{array}{l}\text { 1.5.7. Troubles minéraux de } \\
\text { l'alimentation (manque et excès). }\end{array}$ \\
\hline 1.6.7.1. Potasio. & 1.5.7.1. Potassium. \\
\hline 1.6.7.2. Magnesio. & 1.5.7.2. Magnesium. \\
\hline 1.6.7.3. Azufre. & 1.5.7.3. Soufre. \\
\hline 1.6.7.4. Boro. & 1.5.7.4. Bore. \\
\hline 1.6.7.5. Zinc. & 1.5.7.5. Zinc. \\
\hline 1.6.7.6. Manganeso. & 1.5.7.6. Manganèse. \\
\hline 1.6.8. Salinidad del suelo. & 1.5.8. Toxicité saline. \\
\hline 1.6.9. Necrosis del raquis. & 1.5.9. Asphyxie radiculaire. \\
\hline 2. PARASITOLOGÍA. & 2. PARASITOLOGIE. \\
\hline 2.1. Insectos que atacan a las HOJAS. & 2.1. Insectes qui attaquent les FEUILLES: \\
\hline $\begin{array}{c}\text { 2.1.1. Eriophyes vitis Pgst } \\
\text { (Ácaro Erineum, Arador o Erinosis). }\end{array}$ & $\begin{array}{l}\text { 2.1.1. Eriophyes vitis Pgst. } \\
\text { (Erinose). }\end{array}$ \\
\hline $\begin{array}{l}\text { 2.1.2. Celerio lineata Fabr. } \\
\text { (Esfíngido de la vid). }\end{array}$ & $\begin{array}{l}\text { 2.1.2. Celerio lineata Fabr. } \\
\text { (Sphinx de la vigne). }\end{array}$ \\
\hline $\begin{array}{l}\text { 2.1.3. Byctiscus betulae } \\
\text { (Cigarrero). }\end{array}$ & $\begin{array}{l}\text { 2.1.3. Byctiscus betulae } \\
\text { (Cigarier). }\end{array}$ \\
\hline $\begin{array}{l}\text { 2.1.4. Bromius obscurus L. } \\
\text { (Escribano de la vid). }\end{array}$ & $\begin{array}{l}\text { 2.1.4. Bromius obscurus L. } \\
\text { (Gribouri ou écrivain). }\end{array}$ \\
\hline
\end{tabular}


ENTREC ULTURAS Número 1. ISSN: 1989-5097. Fecha de publicación: 27-03-2009

\begin{tabular}{|c|c|}
\hline $\begin{array}{l}\text { 2.1.5. Eotetranychus carpini } \\
\text { (Araña Amarilla). }\end{array}$ & $\begin{array}{l}\text { 2.1.5. Eotetranychus carpini } \\
\text { (Araignée jaune). }\end{array}$ \\
\hline $\begin{array}{l}\text { 2.1.6. Tetranychus telarius o } \\
\text { Tetranychus urticae (Araña amarilla } \\
\text { común, Telaraña o Araña de dos } \\
\text { manchas). }\end{array}$ & $\begin{array}{l}\text { 2.1.6. Tetranychus telarius o } \\
\text { Tetranychus urticae (Araignée jaune } \\
\text { comun, Tetranyque, Tisserand). }\end{array}$ \\
\hline 2.1.7. Panonychus ulmi (Araña & $\begin{array}{l}\text { 2.1.7. Panonychus ulmi (Araignée } \\
\text { Rouge). }\end{array}$ \\
\hline $\begin{array}{l}\text { 2.2. Insectos que atacan a las FLORES y a } \\
\text { los FRUTOS. }\end{array}$ & $\begin{array}{l}\text { 2.2. Insectes qui attaquent les FLEURS et } \\
\text { les FRUITS. }\end{array}$ \\
\hline $\begin{array}{l}\text { 2.2.1. Hoplia collipyge (Escarabajo } \\
\text { Hoplia). }\end{array}$ & 2.2.1. Hoplia collipyge (Hoplia). \\
\hline $\begin{array}{l}\text { 2.2.2. Pscudococcus maritinus } \\
\text { Ehrhorn (Piojo Harinoso). }\end{array}$ & $\begin{array}{l}\text { 2.2.2. Pscudococcus maritinus } \\
\text { Ehrhorn (Cochenille farineuse). }\end{array}$ \\
\hline $\begin{array}{l}\text { 2.2.3. Drepanothrips reuteri } \\
\text { (Trips). }\end{array}$ & $\begin{array}{l}\text { 2.2.3. Drepanothrips reuteri } \\
\text { Thrips). }\end{array}$ \\
\hline $\begin{array}{l}\text { 2.2.4. Euchistus conspersus Uhler } \\
\text { (Chinche Apestosa). }\end{array}$ & 2.2.4. Euchistus conspersus Uhler. \\
\hline $\begin{array}{l}\text { 2.2.5. Macrodactylus subspinosus } \\
\text { Fabr. (Escoriador de la Rosa o Frailecillo). }\end{array}$ & 2.2.5. Macrodactylus subspinosus \\
\hline $\begin{array}{l}\text { 2.2.6. Contarina Johnsoni Sling } \\
\text { (Mosca de la Flor de la Vid). }\end{array}$ & $\begin{array}{l}\text { 2.2.6. Contarina Johnsoni Sling } \\
\text { (Cecidomye). }\end{array}$ \\
\hline $\begin{array}{l}\text { 2.2.7. Polychrosis viteana Clem } \\
\text { (Palomica de la Vid). }\end{array}$ & 2.2.7. Polychrosis viteana Clem. \\
\hline $\begin{array}{l}\text { 2.2.8. Graponius inaequalis Say } \\
\text { (Picudo o Curculiónido de la Vid). }\end{array}$ & 2.2.8. Graponius inaequalis Say. \\
\hline $\begin{array}{l}\text { 2.2.9. Clysia ambiguella (Cochilis, } \\
\text { Polilla de la vid, Polilla del racimo). }\end{array}$ & 2.2.9. Clysia ambiguella (Cochylis). \\
\hline $\begin{array}{l}\text { 2.2.1.0. Lobesia botrana (Eudemis } \\
\text { o Palomilla del Racimo). }\end{array}$ & $\begin{array}{l}\text { 2.2.1.0. Lobesia botrana } \\
\text { (Eudemys) }\end{array}$ \\
\hline $\begin{array}{l}\text { 2.2.1.1. Sparganothis pilleriana } \\
\text { (Piral o Palomilla de la Vid). }\end{array}$ & $\begin{array}{l}\text { 2.2.1.1. Sparganothis pilleriana } \\
\text { (Pyrale ou Ver de la Vigne). }\end{array}$ \\
\hline $\begin{array}{l}\text { 2.2.1.2. Ceratitis capitata wied } \\
\text { (Mosca de la Fruta del Mediterráneo). }\end{array}$ & 2.2.1.2. Ceratitis capitata wied. \\
\hline $\begin{array}{l}\text { 2.2.1.3. Phyctinus callosus Bohem } \\
\text { (Calendra). }\end{array}$ & $\begin{array}{l}\text { 2.2.1.3. Phyctinus callosus Bohem } \\
\text { (Calendre). }\end{array}$ \\
\hline $\begin{array}{l}\text { 2.2.1.4. Drosophila melanogaster } \\
\text { Meig (Drosófila). }\end{array}$ & $\begin{array}{l}\text { 2.2.1.4. Drosophila melanogaster } \\
\text { Meig (Drosophile) }\end{array}$ \\
\hline $\begin{array}{l}\text { 2.3. Insectos que atacan a las YEMAS y } \\
\text { BROTES JÓVENES. }\end{array}$ & $\begin{array}{l}\text { 2.3. Insectes qui attaquent les } \\
\text { BOURGEONS. }\end{array}$ \\
\hline
\end{tabular}


ENTRECULTURAS Número 1. ISSN: 1989-5097. Fecha de publicación: 27-03-2009

\begin{tabular}{|c|c|}
\hline 2.3.1. Noctuidos o Gusanos grises. & 2.3.1. Noctuelles ou Vers gris. \\
\hline $\begin{array}{l}\text { 2.3.1.1. Agrotis } \\
\text { segetum. }\end{array}$ & 2.3.1.1. Agrotis segetum. \\
\hline 2.3.1.2. Agrotis pronuba. & 2.3.1.2. Agrotis pronuba. \\
\hline 2.3.1.3. Agrotis ypsilon. & 2.3.1.3. Agrotis ypsilon. \\
\hline 2.3.1.4. Agrotis & 2.3.1.4. Agrotis \\
\hline $\begin{array}{c}\text { 2.3.2. Glypfoscelis squamulata } \\
\text { Crotch (Escarabajo de la Yema de la Vid). }\end{array}$ & 2.3.2. Glypfoscelis squamulata \\
\hline $\begin{array}{l}\text { 2.3.3. Haltica ampelofaga } \\
\text { (Escarabajo Altisa o Altica, azulilla, blaveta, } \\
\text { coco, coquillo, corocha, escarabajo, pulga, } \\
\text { roe, saltirón). }\end{array}$ & 2.3.3. Haltica ampelofaga (Altise). \\
\hline $\begin{array}{l}\text { 2.3.4. Limonius Canus leConte } \\
\text { (Escarabajo de Chasquido). }\end{array}$ & 2.3.4. Limonius Canus leConte. \\
\hline $\begin{array}{l}\text { 2.4. Insectos que atacan a las PARTES } \\
\text { PERMANENTES de la vid. }\end{array}$ & $\begin{array}{l}\text { 2.4. Insectes qui attaquent les PARTIES } \\
\text { PERMANENTES de la vigne. }\end{array}$ \\
\hline $\begin{array}{l}\text { 2.4.1. Scobicia declivis leConte } \\
\text { (Barrenador de los cables de plomo). }\end{array}$ & 2.4.1. Scobicia declivis leConte. \\
\hline $\begin{array}{l}\text { 2.4.2. Amphicerus bicandatus Say } \\
\text { (Barrenador del sarmiento de la vid, } \\
\text { Barrenador de los vástagos del manzano). }\end{array}$ & 2.4.2. Amphicerus bicandatus Say. \\
\hline $\begin{array}{l}\text { 2.4.3. Polycaon confertus leConte } \\
\text { (Barrenador de ramas y vástagos). }\end{array}$ & $\begin{array}{l}\text { 2.4.3. Polycaon confertus } \\
\text { leConte. }\end{array}$ \\
\hline $\begin{array}{c}\text { 2.4.4. Sinoxylon sexdentatum } \\
\text { Olivier Barrenillo (barreneta o carcoma). }\end{array}$ & $\begin{array}{l}\text { 2.4.4. Sinoxylon sexdentatum } \\
\text { Olivier. }\end{array}$ \\
\hline $\begin{array}{l}\text { 2.4.5. Insectos escamas o } \\
\text { lecaninos. }\end{array}$ & 2.4.5. Écailles. \\
\hline $\begin{array}{l}\text { 2.4.5.1. Lecanium corni } \\
\text { (Escama Café del Chabacano). }\end{array}$ & $\begin{array}{ll} & \text { 2.4.5.1. Lecanium corni } \\
\text { (Cochenille du } & \text { Cornouiller). }\end{array}$ \\
\hline $\begin{array}{l}\text { 2.4.5.2. Pulvinaria vitis } \\
\text { (Escama Algodonosa del Arce). }\end{array}$ & $\begin{array}{ll}\text { 2.4.5.2. Pulvinaria vitis } \\
\text { (Cochenille flon conneuse, Cochenille } \\
\text { rouge). }\end{array}$ \\
\hline $\begin{array}{l}\text { 2.4.5.3. Dispidiotus uvae } \\
\text { (Escama de la Vid). }\end{array}$ & 2.4.5.3. Dispidiotus uvae. \\
\hline $\begin{array}{l}\text { 2.4.6. Reticulitermes hasperus } \\
\text { Banks (Termita subterránea). }\end{array}$ & $\begin{array}{l}\text { 2.4.6. Reticulitermes hasperus } \\
\text { Banks (Fourmi Blanche). }\end{array}$ \\
\hline $\begin{array}{l}\text { 2.4.7. Platypedia minor Uhler } \\
\text { (Chicharras). }\end{array}$ & $\begin{array}{l}\text { 2.4.7. Platypedia minor Uhler } \\
\text { (Cigale). }\end{array}$ \\
\hline 2.4.8. Vesperus xatarti & 2.4.8. Vesperus xatarti (Le \\
\hline
\end{tabular}


ENTREC ULTURAS Número 1. ISSN: 1989-5097. Fec ha de publicación: 27-03-2009

\begin{tabular}{|c|c|}
\hline (Castañeta). & vespère). \\
\hline $\begin{array}{l}\text { 2.5. Insectos que atacan a las } \\
\text { RAICES. }\end{array}$ & $\begin{array}{l}\text { 2.5. Insectes qui attaquent les } \\
\text { RACINES. }\end{array}$ \\
\hline $\begin{array}{l}\text { 2.5.1. Phylloxera vertratix } \\
\text { (Filoxera). }\end{array}$ & $\begin{array}{l}\text { 2.5.1. Phylloxera vertratix } \\
\text { (Phylloxera). }\end{array}$ \\
\hline $\begin{array}{l}\text { 2.5.2. Meloidogyne incognita Var } \\
\text { (Nemátodo del Nudo de la Raiz, Nemátodo } \\
\text { agallador, Nemátodo nodulador). }\end{array}$ & $\begin{array}{l}\text { 2.5.2. Meloidogyne incognita Var } \\
\text { (Nématode à galles, Nématode cécidogène, } \\
\text { Nématode des racines noueuses). }\end{array}$ \\
\hline $\begin{array}{l}\text { 2.5.3. Pratylenchus nulnus Allen } \\
\text { \& Jensen (Nemátodo de la Lesión de la } \\
\text { Raiz). }\end{array}$ & $\begin{array}{c}\text { 2.5.3. Pratylenchus nulnus Allen } \\
\text { \& Jensen (Nématode des lésions racinaires). }\end{array}$ \\
\hline $\begin{array}{l}\text { 2.5.4. Xiphinema index } \\
\text { (Nemátodo de Daga). }\end{array}$ & $\begin{array}{l}\text { 2.5.4. Xiphinema index } \\
\text { (Xiphinema). }\end{array}$ \\
\hline $\begin{array}{l}\text { 2.5.5. Longidorus spp. } \\
\text { (Nemátodo de aguja). }\end{array}$ & $\begin{array}{l}\text { 2.5.5. Longidorus ssp. (Nématode } \\
\text { aiguille). }\end{array}$ \\
\hline $\begin{array}{l}\text { 2.5.6. Paratylenchus ssp. } \\
\text { (Nemátodo alfiler). }\end{array}$ & $\begin{array}{l}\text { 2.5.6. Paratylenchus ssp. } \\
\text { (Nématode épingle). }\end{array}$ \\
\hline $\begin{array}{l}\text { 2.5.7. Helientylenchus ssp. } \\
\text { (Nemátodo espiral). }\end{array}$ & $\begin{array}{l}\text { 2.5.7. Helientylenchus ssp. } \\
\text { (Nématode spiralé). }\end{array}$ \\
\hline $\begin{array}{l}\text { 2.5.8. Paratrichodorus christiel } \\
\text { (Nemátodo atrofiador de raíces). }\end{array}$ & $\begin{array}{l}\text { 2.5.8. Paratrichodorus christiel. } \\
\text { (Nématode des racines tronqués). }\end{array}$ \\
\hline $\begin{array}{l}\text { 2.5.9. Adoxus obscurus (Gusano } \\
\text { occidental de la Raiz de la Vid). }\end{array}$ & 2.5.9. Adoxus obscurus. \\
\hline $\begin{array}{l}\text { 2.5.10. Margarodes vitium (Perlas } \\
\text { del suelo). }\end{array}$ & 2.5.10. Margarodes vitium. \\
\hline $\begin{array}{l}\text { 2.6. Insectos que atacan a las } \\
\text { PASAS. }\end{array}$ & $\begin{array}{l}\text { 2.6. Insectes qui attaquent les } \\
\text { RAISINS. }\end{array}$ \\
\hline $\begin{array}{l}\text { 2.6.1. Ephestia figulilella } \\
\text { (Palomilla de la Pasa). }\end{array}$ & 2.6.1. Ephestia figulilella. \\
\hline $\begin{array}{l}\text { 2.6.2. Plodia interponctella } \\
\text { (Palomilla India de la Harina, Palomilla } \\
\text { Bandeada). }\end{array}$ & 2.6.2. Plodia interponctella. \\
\hline $\begin{array}{l}\text { 2.6.3. Oryzaephilus surinamensis } \\
\text { (Gorgojo Aserrado de los granos). }\end{array}$ & 2.6.3. Oryzaephilus surinamensis. \\
\hline $\begin{array}{l}\text { 2.7. Plagas producidas por } \\
\text { VERTEBRADOS Y GASTERÓPODOS. }\end{array}$ & $\begin{array}{l}\text { 2.7. Fléaux provoqués par } \\
\text { VERTÉBRÉS et GASTÉROPODES. }\end{array}$ \\
\hline 2.7.1. Conejos y liebres. & 2.7.1. Lapins et lièvres. \\
\hline 2.7.2. Caracoles. & 2.7.2. Escargots. \\
\hline 2.7.3. Jabalíes. & 2.7.3. Sangliers. \\
\hline 2.7.4. Palomas. & 2.7.4. Pigeons. \\
\hline 2.7.5. Pájaros. & 2.7.5. Oiseaux. \\
\hline
\end{tabular}


ENTREC ULTURAS Número 1. ISSN: 1989-5097. Fecha de publicación: 27-03-2009

\begin{tabular}{|c|c|}
\hline 2.7.5.1. Jilgueros. & 2.7.5.1. Chardonnerets. \\
\hline 2.7.5.2. Estorninos. & 2.7.5.2. Étourneaux. \\
\hline 2.7.6. Topos. & 2.7.6. Taupes. \\
\hline
\end{tabular}

\section{ÍNDICE DE TÉRMINOS}

El índice comprende cada uno de los términos que se presentan en el sistema conceptual, al igual que un gran número de sinónimos y demás términos relevantes que se encuentran normalmente en el contexto del que han sido extraídos, todos ellos ordenados alfabética y numéricamente.

Hay que tener en cuenta que este índice está redactado del español al francés. Por lo tanto es necesario, a la hora de buscar un equivalente, se debe comenzar por el término en español. En el caso de que dirigiéramos la búsqueda desde el francés al español, podríamos encontrar el equivalente, pero el proceso sería más dificultoso.

El índice funciona de la siguiente forma:

a) Si el término español en cuestión no posee ningún sinónimo o se trata de un "término base" dentro de un grupo de sinónimos, a su izquierda aparecen los equivalentes en lengua francesa. En el caso de los términos de Parasitología aparece antes la denominación científica.

b) Si se trata de un sinónimo, su equivalente consistirá en un segundo término en español ("término base") precedido por un asterisco, que incluirá los equivalentes en lengua francesa.

\begin{tabular}{|c|c|}
\hline 1. Acariosis & Calepitrimerus vitis Nal. Acariose \\
\hline 2. Ácaro de la roña & Brevipalpus lewisi mcgregor \\
\hline 3. Ácaro del pacífico & Tetranychus pacificus \\
\hline 4. Ácaro erineum & $*$ Erinosis \\
\hline 5. Ácaro mohoso de la uva & Calepitremeris vitis Can. \\
\hline 6. Aceitero & * Sardiñeiro \\
\hline 7. Acidez del suelo & Acidité du sol. Sol acide \\
\hline 8. Agalla & Galle \\
\hline 9. Agalla de la corona & Broussin parasite \\
\hline 10. Agostamiento & Aoûtement \\
\hline 11. Algodón & * Melazo \\
\hline 12. Almidón & Amidon \\
\hline 13. Altica & Haltica ampelofaga. Altise \\
\hline
\end{tabular}


ENTRECULTURAS Número 1. ISSN: 1989-5097. Fecha de publicación: 27-03-2009

\begin{tabular}{|c|c|}
\hline 14. Amarilleamientos de la vid & Panachure \\
\hline 15. Anillo & Bourrelet \\
\hline 16. Anteridio & Anthéridie \\
\hline 17. Antracnosis & $\begin{array}{l}\text { Anthracnose maculée. Charbon. Black } \\
\text { spot. Ripe Rot }\end{array}$ \\
\hline 18. Apoplejía parasitaria & Apoplexie. Esca \\
\hline 19. Arador & * Erinosis \\
\hline 20. Araña amarilla & $\begin{array}{l}\text { Eotetranychus carpini Oud. Araignée } \\
\text { jaune }\end{array}$ \\
\hline 21. Araña amarilla común & $\begin{array}{l}\text { Tetranychus urticae Koch. } \\
\text { Tetranyque } \\
\text { Tisserand. Acarien jaune commun }\end{array}$ \\
\hline 22. Araña de dos manchas & * Araña amarilla común \\
\hline 23. Araña roja & $\begin{array}{l}\text { Panonychus ulmi Koch. Araignée } \\
\text { rouge vrai }\end{array}$ \\
\hline 24. Ascospora & Ascospore \\
\hline 25. Asurado & * Escaldado \\
\hline 26. Azufre & Soufre \\
\hline 27. Azulilla & $*$ Altica \\
\hline 28. Bacteria & Bactérie \\
\hline 29. Barrenador de los cables de plomo & Scobicia declivis leconte \\
\hline $\begin{array}{l}\text { 30. Barrenador de los vástagos del } \\
\text { manzano }\end{array}$ & Amphicerus bicandatus Say \\
\hline 31. Barrenador de ramas y vástagos & Polycaonconfertus leconte \\
\hline 32. Barrenador del sarmiento de la vid & $\begin{array}{l}\text { * Barrenador de los vástagos del } \\
\text { manzano }\end{array}$ \\
\hline 33. Barreneta & $*$ Barrenillo \\
\hline 34. Barrenillo & Sinoxilon sexdentatum \\
\hline 35. Bastoncillo & Batonnet \\
\hline 36. Baya & Baie \\
\hline 37. Blabeta & $*$ Altica \\
\hline 38. Black-Rot & Black-Rot. Pourriture maculée \\
\hline 39. Boro & Bore \\
\hline 40. Botón floral & Bouton floral \\
\hline 41. Brazo & Bras \\
\hline 42. Brazo muerto & $*$ Eutypiose \\
\hline 43. Brenner & Brenner. Rougeot parasite \\
\hline 44. Brote & Bourgeon \\
\hline 45. Calendra & Phyctinus callosus Bohem. Calendre \\
\hline 46. Caracoles & Escargots \\
\hline 47. Carcoma & * Barrenillo \\
\hline
\end{tabular}


ENTREC ULTURAS Número 1. ISSN: 1989-5097. Fecha de publicación: 27-03-2009

\begin{tabular}{|c|c|}
\hline 48. Caries blanca & * Podredumbre blanca \\
\hline 49. Carraleja & * Castañeta \\
\hline 50. Castañeta & Vesperus xatarti. Vespère \\
\hline 51. Castañuela & * Castañeta \\
\hline 52. Cenicilla & * Oidio \\
\hline 53. Cepa & Cep, cepage \\
\hline 54. Chancro & Chancre \\
\hline 55. Chicharra & Platypedia minor Uhler. Cigale \\
\hline 56. Chinche apestosa & Euchistus conspersus Uhler \\
\hline 57. Cicadélido africano & * Mosquito verde \\
\hline 58. Cicadelles & Insectos homópteros \\
\hline 59. Cigarrero & Byctiscus betulae. Cigarier \\
\hline 60. Clorosis caliza & Chlorose \\
\hline 61. Cochilis & * Polilla de la vid \\
\hline 62. Cochinilla algodonosa & * Melazo \\
\hline 63. Cochinilla blanca & * Melazo \\
\hline 64. Coco & * Altica \\
\hline 65. Coloración & Coloration \\
\hline 66. Cordón endocelular & Cordon endocellulaire \\
\hline 67. Conejos & Lapins \\
\hline 68. Conidio/a & Conidie \\
\hline 69. Conidióforo & Conidiophore \\
\hline 70. Contaminación & Contamination \\
\hline 71. Coquillo & * Altica \\
\hline 72. Corcho & Liège \\
\hline 73. Corocha & * Altica \\
\hline 74. Corola & Corolle \\
\hline 75. Corrimiento de la Vid & Coulure \\
\hline 76. Corteza & Écorce \\
\hline 77. Corteza corchosa & Écorce liégeuse \\
\hline 78. Cosecha & Récolte \\
\hline 79. Cotiledón & Cotylédon \\
\hline 80. Crisálida & Chrysalide \\
\hline 81. Cromofila & Chromophile \\
\hline 82. Curculiónido de la vid & Graponius inaequalis Say \\
\hline 83. Daño & Dégât \\
\hline 84. Daños por el viento & Folletage \\
\hline 85. Decoloración & Décoloration \\
\hline 86. Defoliación & Défoliation \\
\hline 87. Desborre & Débourrement \\
\hline
\end{tabular}


ENTREC ULTURAS Número 1. ISSN: 1989-5097. Fecha de publicación: 27-03-2009

\begin{tabular}{|c|c|}
\hline 88. Descarnador de las hojas & * Esqueletonizador \\
\hline 89. Desecación & Déssiccation \\
\hline 90. Desecación del raquis o raspón & Asphyxie radiculaire \\
\hline 91. Deutoninfa & Deutonymphe \\
\hline 92. Diseminación & Dissémination \\
\hline 93. Doblador de la vid & Desmia funeralis Hübner \\
\hline 94. Dormilones & * Gusanos grises \\
\hline 95. Drosofila & $\begin{array}{lll}\text { Drosophila melanogaster Meig. } \\
\text { Drosophile }\end{array}$ \\
\hline 96. Eclosión & Éclosion \\
\hline 97. Eflorescencia & Efflorescence \\
\hline 98. Encrespamiento de la hoja & Court-noué. GFV \\
\hline 99. Enfermedad criptogámica & Maladie cryptogamique \\
\hline 100. Enfermedad de Pierce & Maladie de Pierce \\
\hline 101. Enrojecimiento & Rougeau \\
\hline 102. Enrollamiento de la hoja & Enroulement \\
\hline 103. Erinosis & Eriophyes vitis Pgst. Erinose \\
\hline 104. Escaldado & Grillage. Coup de soleil. Échaudage \\
\hline 105. Escama Algodonosa del Arce & $\begin{array}{l}\text { Pulvinaria vitis. Cochenille } \\
\text { flonconneuse. Cochenille rouge }\end{array}$ \\
\hline 106. Escama Café del Chabacano & $\begin{array}{l}\text { Lecanium corni. Cochenille du } \\
\text { Cornouiller }\end{array}$ \\
\hline 107. Escama de la vid & Dispidiotus uvae \\
\hline 108. Escarabajillo & $*$ Gorgojo \\
\hline 109. Escarabajo & * Altica \\
\hline 110. Escarabajo de chasquido & Limonius Canus leconte \\
\hline 111. Escarabajo de la yema de la vid & Glypfoscelis squamulata Crotch \\
\hline 112. Escarabajo de Mayo & * Rosquilla \\
\hline 113. Escarabajuelo & * Altica \\
\hline 114. Escarabatet & * Altica \\
\hline 115. Esclerocio & Sclérote \\
\hline 116. Escoriador de la rosa & $*$ Frailecillo \\
\hline 117. Escribano de la vid & $\begin{array}{l}\text { Bromius obscurus. Écrivain ou } \\
\text { Gribouri }\end{array}$ \\
\hline 118. Esfíngido de la vid & $\begin{array}{l}\text { Celerio lineata var. Livornica Esp. } \\
\text { Sphinx de la vigne }\end{array}$ \\
\hline 119. Espora & Spore \\
\hline 120. Esqueletonizador & Harrisina brillians B. \\
\hline 121. Estados ninfales o mudas & Mues \\
\hline 122. Estilospora & Stylospore \\
\hline 123. Estoma & Stomate \\
\hline
\end{tabular}


ENTREC ULTURAS Número 1. ISSN: 1989-5097. Fecha de publicación: 27-03-2009

\begin{tabular}{|c|c|}
\hline 124. Estorninos & Étourneaux \\
\hline 125. Eudemis & * Palomilla del racimo \\
\hline 126. Eulecanium cornibouch & $\begin{array}{l}\text { Eulecanium cornibouch. Cochenille } \\
\text { du cornouiller }\end{array}$ \\
\hline 127. Eulecanium persicae Fab. & Eulecanium persicae Fab. \\
\hline 128. Eulia & Eulia pulchellana. Eulia \\
\hline 129. Eutipiosis & Eutypiose \\
\hline 130. Exceso de agua & Excès d'eau \\
\hline 131. Excoriosis & Excoriose \\
\hline 132. Falsa chinche pequeña & Nysius ericae Shiling \\
\hline 133. Fasciación & Fasciation \\
\hline 134. Fecundación & Fécondation \\
\hline 135. Filoxera & Phylloxera vastratix. Phylloxera \\
\hline 136. Flavescencia dorada & Flavescence dorée \\
\hline 137. Floración & Floraison \\
\hline 138. Follage & Feuillage \\
\hline 139. Frailecillo & Macrodactilus subspinosus Fabr. \\
\hline 140. Fruto & Fruit \\
\hline 141. Fundadora & Fondatrice \\
\hline 142. Gajo & Bouture \\
\hline 143. Gallinorba & * Castañeta \\
\hline 144. Gata & * Piral \\
\hline 145. Generaciones gallícolas & Gallicoles \\
\hline 146. Germen & Germe \\
\hline 147. Germinación & Germination \\
\hline 148. Gorgojo aserrado de los granos & Orizaephilus surinamensis. Charançon \\
\hline 149. Granizo & Grêle \\
\hline 150. Grano & Grain \\
\hline 151. Grano de arroz & Holocacista rivillei Stl. \\
\hline 152. Gusano & Ver \\
\hline 153. Gusano blanco (1) & * Castañeta \\
\hline 154. Gusano blanco (2) & * Rosquilla \\
\hline 155. Gusano gris (1) & $\begin{array}{l}\text { Agrotis segetum Schiff. Vers gris ou } \\
\text { noctuelles }\end{array}$ \\
\hline 156. Gusano gris (2) & $\begin{array}{l}\text { Agrotis exclamationis L. Vers gris ou } \\
\text { noctuelles }\end{array}$ \\
\hline 157. Gusano gris (3) & $\begin{array}{l}\text { Agrotis ypsilon Rott. Vers gris ou } \\
\text { noctuelles }\end{array}$ \\
\hline 158. Gusano gris (4) & $\begin{array}{l}\text { Agrotis exclamationis. Vers gris ou } \\
\text { noctuelles }\end{array}$ \\
\hline 159. Gusano occidental de la raíz de la & Adoxus obscurus \\
\hline
\end{tabular}


ENTREC ULTURAS Número 1. ISSN: 1989-5097. Fecha de publicación: 27-03-2009

\begin{tabular}{|c|c|}
\hline vid & \\
\hline 160. Gusano verde & * Piral \\
\hline 161. Gusarapo & $*$ Piral \\
\hline 162. Helada & Gelée \\
\hline 163. Hembra & Femelle \\
\hline 164. Hoja & Feuille \\
\hline 165. Hongo & Champignon \\
\hline 166. Hoplia & Hoplia collipyge. Hoplia \\
\hline 167. Hormiga blanca & * Termita \\
\hline 168. Huevo de invierno & Oeuf d'hiver \\
\hline 169. Incubación & Incubation \\
\hline 170. Infección & Infection \\
\hline 171. Inflorescencia & Inflorescence \\
\hline 172. Injerto & Greffon, greffe \\
\hline 173. Jabalíes & Sangliers \\
\hline 174. Jilgueros & Chardonnerets \\
\hline 175. Lagarta & * Piral \\
\hline 176. Langostas & Sauterelles \\
\hline 177. Larvas & Larves \\
\hline 178. Lecaninos o insectos escama & Écailles \\
\hline 179. Lesión & Lésion \\
\hline 180. Liebres & Lièvres \\
\hline 181. Limbo & Limbe \\
\hline 182. Lobillos & * Gusanos grises \\
\hline 183. Lóbulo & Lobe \\
\hline 184. Macho & Mâle \\
\hline 185. Maduración & Maturation \\
\hline 186. Magnesio & Magnesium \\
\hline 187. Mal negro & * Podredumbre cladosporium \\
\hline 188. Mal nero & * Tizón \\
\hline 189. Maladie d'Oléron & * Tizón \\
\hline 190. Malduermes & * Gusanos grises \\
\hline 191. Mancha & Tache \\
\hline 192. Mancha foliar por Cercospora & Cercosporiose \\
\hline 193. Mancha foliar por Septoria & Mélanose \\
\hline 194. Manchas de aceite & Taches d'huile \\
\hline 195. Manganeso & Manganèse \\
\hline 196. Marchitamiento & Flétrissement, flétrissure \\
\hline 197. Mariposa & Papillon \\
\hline 198. Melazo & Pseudococcus citri Risso. Cotonet. \\
\hline
\end{tabular}


ENTREC ULTURAS Número 1. ISSN: 1989-5097. Fecha de public ación: 27-03-2009

\begin{tabular}{|c|c|}
\hline & Cochenille farineuse \\
\hline 199. Melolonta & * Rosquilla \\
\hline 200. Micelio & Mycélium \\
\hline 201. Mildio negro & * Apoplejía \\
\hline 202. Mildiu & Mildiou \\
\hline 203. Moho & Moisissure \\
\hline 204. Moho gris & * Podredumbre gris \\
\hline 205. Mongueta & * Castañeta \\
\hline 206. Mosaico amarillo & Yellow mosaic. HCYMV \\
\hline 207. Mosaico asteroide & Mosaïque étoilée \\
\hline 208. Mosca de la flor de la vid & Contarina johnsoni sling.cecydome \\
\hline 209. Mosca de la fruta & * Mosca del mediterráneo \\
\hline 210. Mosca del mediterráneo & Ceratitis capitata Wied \\
\hline 211. Mosca del vinagre & $\begin{array}{lll}\text { Drosophila melanogaster Meigen. } \\
\text { Drosophile }\end{array}$ \\
\hline 212. Mosquito verde & Empoasca lybica Berg. \\
\hline 213. Necrosis & Nécrose \\
\hline 214. Necrosis bacteriana & * Tizón \\
\hline 215. Necrosis del raquis & Asphyxie radiculaire \\
\hline 216. Nemátodo & Nématode \\
\hline 217. Nemátodo agallador & * Nemátodo nodulador \\
\hline 218. Nemátodo aguja & Longidorus spp. Nématode aiguille \\
\hline 219. Nemátodo alfiler & Paratylenchus ssp. Nématode épingle \\
\hline 220. Nemátodo atrofiador de raíces & $\begin{array}{l}\text { Paratrichodorus christiel. Nématode } \\
\text { des racines tronqués }\end{array}$ \\
\hline 221. Nemátodo de daga & Xiphinema index. Xiphinema \\
\hline 222. Nemátodo de la lesión de la raíz & $\begin{array}{l}\text { Pratylenchus nulnus Allen \& Jensen. } \\
\text { Nématode des lésions racinaires }\end{array}$ \\
\hline 223. Nemátodo del nudo de la raíz & * Nemátodo nodulador \\
\hline 224. Nemátodo espiral & $\begin{array}{l}\begin{array}{l}\text { Helientylenchus ssp. Nématode } \\
\text { espiralé }\end{array} \\
\end{array}$ \\
\hline 225. Nemátodo nodulador & $\begin{array}{l}\text { Meloidogyne incognita Var. } \\
\text { Nématode à galles } \\
\text { Nématode cécidogène. Nématode des } \\
\text { racines noueuses }\end{array}$ \\
\hline 226. Nervio & Nervure \\
\hline 227. Ninfa & Nymphe \\
\hline 228. Noctuidos & * Gusanos grises \\
\hline 229. Nudo & Noeud \\
\hline 230. Nudo negro & * Agalla de la corona \\
\hline 231. Oidio & Ö̈dium \\
\hline
\end{tabular}


ENTREC ULTURAS Número 1. ISSN: 1989-5097. Fecha de publicación: 27-03-2009

\begin{tabular}{|c|c|}
\hline 232. Oogonio & Oogone \\
\hline 233. Oruga & Chenille \\
\hline 234. Oruga de esteva & * Esfíngido de la vid \\
\hline 235. Oruga peluda & $\begin{array}{l}\text { Ocnogina baetica Ramb. Chenille } \\
\text { bourrue }\end{array}$ \\
\hline 236. Pájaros & Oiseaux \\
\hline 237. Pajuela & * Piral \\
\hline 238. Palomas & Pigeons \\
\hline 239. Palomica de la vid & Polychrosis viteana Clem. \\
\hline 240. Palomilla bandeada & Plodia interponctella \\
\hline 241. Palomilla de la pasa & Ephesia figulilella \\
\hline 242. Palomilla de la vid & * Piral \\
\hline 243. Palomilla del racimo & $\begin{array}{l}\text { Lobesia botrana. Cuc de raim ou } \\
\text { Eudemys }\end{array}$ \\
\hline 244. Palomilla india de la harina & * Palomilla bandeada \\
\hline 245. Pámpano & Feuille de vigne, pampre \\
\hline 246. Parásito & Parasite \\
\hline 247. Parasitología & Parasitologíe \\
\hline 248. Parpadeado & Chlorose \\
\hline 249. Partenogenesis & Parthénogénèse \\
\hline 250. Patología & Pathologie \\
\hline 251. Pecíolo & Pétiole \\
\hline 252. Pedicelo & Pédicelle \\
\hline 253. Pedreses & $*$ Pedrolo \\
\hline 254. Pedrolo & Cneorrhinus dispar Graells \\
\hline 255. Pedúnculo & Pédoncule \\
\hline 256. Peritecio & Périthèce \\
\hline 257. Perlas del suelo & Margarodes vitium \\
\hline 258. Pholus achemon Drury & $\begin{array}{l}\text { Pholus achemon Drury. Sphinx } \\
\text { achemon }\end{array}$ \\
\hline 259. Picnidio & Pycnide \\
\hline 260. Picudo & * Curculiónido de la vid \\
\hline 261. Pigmentación & Pigmentation \\
\hline 262. Piojo harinoso & $\begin{array}{l}\text { Pscudococcus maritinus Enhorn. } \\
\text { Cochenille farineuse }\end{array}$ \\
\hline 263. Piral & $\begin{array}{l}\text { Sparganothis pilleriana Schiff. Pirale. } \\
\text { Cuc vert. Vert de la vigne }\end{array}$ \\
\hline 264. Plaga & Fléau \\
\hline 265. Planta de reemplazo & Plant de remplacement \\
\hline 266. Poda & Taille \\
\hline 267. Podredumbre & Pourriture \\
\hline
\end{tabular}


ENTRECULTURAS Número 1. ISSN: 1989-5097. Fecha de publica ción: 27-03-2009

\begin{tabular}{|c|c|}
\hline 268. Podredumbre alternaria & Alternariose \\
\hline 269. Podredumbre blanca & Rot blanc. Coître \\
\hline 270. Podredumbre botrytis & * Podredumbre gris \\
\hline 271. Podredumbre cladosporium & Cladosporiose \\
\hline 272. Podredumbre de la raíz & Pourridié \\
\hline 273. Podredumbre de la raíz Armillaria & Pourridié agaric. Pourridié à armillaire \\
\hline 274. Podredumbre de la raíz del algodón & * Podredumbre Ozonium de la raíz \\
\hline 275. Podredumbre de moho azul & Pourriture amère \\
\hline 276. Podredumbre de moho negro & Pourriture noire \\
\hline 277. Podredumbre del manojo de verano & * Tizón apical de sarmientos \\
\hline $\begin{array}{l}\text { 278. Podredumbre dematophora de la } \\
\text { raíz }\end{array}$ & Pourridié laineux \\
\hline 279. Podredumbre gris & Pourriture grise. Botrytis Cinerea \\
\hline 280. Podredumbre húmeda & * Podredumbre Rhizopus \\
\hline 281. Podredumbre madura y amarga & Bitter rot \\
\hline 282. Podredumbre negra & $*$ Black-Rot \\
\hline 283. Podredumbre Ozonium de la raíz & $\begin{array}{l}\text { Ozonium Root Rot, Texas Root } \\
\text { Rot, Pourridié du coton }\end{array}$ \\
\hline 284. Podredumbre Pythium del collar & * Pudrición del cuello \\
\hline 285. Podredumbre Rhizopus & Pourriture à Rhizopus \\
\hline 286. Podredumbre texana de la raíz & * Podredumbre Ozonium de la raíz \\
\hline 287. Polen & Pollen \\
\hline 288. Polilla de la vid & * Polilla del racimo \\
\hline 289. Polilla del racimo & $\begin{array}{l}\text { Clysia ambiguella HB. Cuc de raim ou } \\
\text { cochylis }\end{array}$ \\
\hline 290. Polinización & Pollinisation \\
\hline 291. Potasio & Potassium \\
\hline 292. Protoninfa & Protonymphe \\
\hline 293. Pudrición blanca & * Podredumbre blanca \\
\hline 294. Pudrición blanca de raíces & $\begin{array}{l}* \text { Podredumbre dematophora de la } \\
\text { raíz }\end{array}$ \\
\hline 295. Pudrición de raíces por Roesleria & Pourridié morille \\
\hline 296. Pudrición del cuello & Pourriture du collet \\
\hline 297. Pudrición negra & * Black-Rot \\
\hline 298. Pudrición por alternaria & * Podredumbre alternaria \\
\hline 299. Pudrición por Cladosporium & * Podredumbre cladosporium \\
\hline 300. Pudrición por hongo azul & * Podredumbre de moho azul \\
\hline 301. Pudrición por Rhizopus & * Podredumbre Rhizopus \\
\hline 302. Puesta & Ponte \\
\hline 303. Pulga & $*$ Altica \\
\hline
\end{tabular}


ENTREC ULTURAS Número 1. ISSN: 1989-5097. Fecha de publicación: 27-03-2009

\begin{tabular}{|c|c|}
\hline 304. Pulgón & * Altica. Puceron \\
\hline 305. Pulguilla & * Altica \\
\hline 306. Pulvinaria vitis L. & $\begin{array}{l}\text { Pulvinaria vitis L. Cochenille } \\
\text { flonconneuse. Cochenille rouge }\end{array}$ \\
\hline 307. Racimo & Grappe \\
\hline 308. Radicícolas & Radicicoles \\
\hline 309. Raíz & Racine \\
\hline 310. Ramo & Rameau \\
\hline 311. Raquitismo & Raboufrissement \\
\hline 312. Rayo & Foudre \\
\hline 313. Rebujadora & * Piral \\
\hline 314. Revoltona & * Piral \\
\hline 315. Roe & * Altica \\
\hline 316. Roe-brotes & * Gorgojo \\
\hline 317. Roña & Rouille \\
\hline 318. Roña española & * Apoplejía \\
\hline 319. Roña negra & * Apoplejía \\
\hline 320. Rosquilla & $\begin{array}{l}\text { Melolontha Melolontha. Hanneton } \\
\text { commun }\end{array}$ \\
\hline 321. "Rostro" de la Filoxera & Le "Rostre" \\
\hline 322. Roya & Rouille de la vigne \\
\hline 323. Salinidad del suelo & Toxicité saline \\
\hline 324. Saltador de la parra & * Mosquito verde \\
\hline 325. Saltamontes Schistocerca vaga Scuder & Schistocerca vaga Scuder \\
\hline 326. Saltamontes verde de los valles & Schistocerca shoshone Thomas \\
\hline 327. Saltiró & * Altica \\
\hline 328. Saneamiento del suelo & Assainissement du sol \\
\hline 329. Sarampión negro & * Apoplejía \\
\hline 330. Sardiñeiro & Lopus sulcatus \\
\hline 331. Sarmiento & Sarment \\
\hline 332. Sarna de la vid & Colomerus vitis Pgst. Erinose \\
\hline 333. Sequedad & Sécheresse \\
\hline 334. Sexúparas aladas & Ailés \\
\hline 335. Soldadura & Soudure \\
\hline 336. Tallo & Tige \\
\hline 337. Tallo circundado & * Pudrición del cuello \\
\hline 338. Tegumento & Tégument \\
\hline 339. Tejido & Tissu \\
\hline 340. Telaraña & * Oruga peluda \\
\hline 341. Telaraña & * Araña amarilla común \\
\hline
\end{tabular}


ENTRECULTURAS Número 1. ISSN: 1989-5097. Fecha de publicación: 27-03-2009

\begin{tabular}{|c|c|}
\hline 342. Termita & $\begin{array}{l}\text { Reticulermes hasperus Banks. Fourmi } \\
\text { Blanche }\end{array}$ \\
\hline 343. Tilos & Thylles \\
\hline 344. Tilosis & Thyllose \\
\hline 345. Tiña & $*$ Piral \\
\hline 346. Tizón & $\begin{array}{l}\text { Nécrose bactérienne. Maladie } \\
\text { d'Oléron. Mal Nero }\end{array}$ \\
\hline 347. Tizón apical de sarmientos & Diplodia dieback \\
\hline 348. Topos & Taupes \\
\hline 349. Trips europeo de la uva & Drepanotrips reuteri Uzel. Thrips \\
\hline 350. Tronco & Tronc, souche \\
\hline 351. Uva & Raisin \\
\hline 352. Vaso & Vaisseau \\
\hline 353. Vena & Veine \\
\hline 354. Vid & Vigne \\
\hline 355. Viento & Vent \\
\hline 356. Vientos cálidos & Vents chauds \\
\hline 357. Vilda & * Castañeta \\
\hline 358. Viña & Vigne \\
\hline 359. Viñedo & Vignoble \\
\hline 360. Virus & Virus \\
\hline 361. Viticultura & Viticulture \\
\hline 362. Yema & Bourgeon \\
\hline 363. Yesca & * Apoplejía \\
\hline 364. Zarcillo & Vrille \\
\hline 365. Zinc & Zinc \\
\hline 366. Zoospora & Zoospore \\
\hline
\end{tabular}

\section{FASE DE TRADUCCIÓN}

La problemática de la traducción de términos sobre Patología y Parasitología de la Vid, caracterizada a su vez por la problemática de los textos especializados científicos y por ciertas peculiaridades propias del dominio de la Viticultura, se resume en una serie de dificultades que vamos a detallar a continuación:

La primera dificultad es la obtención de bibliografía adecuada, textos paralelos y glosarios especializados en ambas lenguas.

La segunda dificultad es la comprensión y asimilación de los conocimientos especializados debido principalmente a la denominada arbitrariedad de los términos científicos (falta de conexión entre el significante 
y el significado), así como la correcta estructuración terminológica de la documentación.

La tercera dificultad, y una de las más complejas, es resolver los problemas de equivalencia entre los términos de los dos idiomas, debido a los numerosos sinónimos que poseen los términos y a las diferencias que existen entre las estructuras conceptuales de ambos países.

La cuarta dificultad es la resolución de la traducción de los términos que no han sido normalizados.

La quinta dificultad consiste en resolver de forma correcta los giros gramaticales, los "falsos amigos" y las expresiones típicas del mundo de la Viticultura.

La sexta dificultad consiste en interpretar adecuadamente y reproducir las referencias culturales (implícitas y explícitas) propias del lugar de origen que poseen los textos de Viticultura.

La séptima dificultad es el tratamiento adecuado de los textos híbridos, no exclusivamente científicos, que surgen como resultado de la fusión del discurso y la terminología de varias disciplinas.

La octava dificultad es la adaptación de la terminología puramente científica en algunos textos semiespecializados o de divulgación a una terminología más asequible para un receptor no experto en la materia (adaptación de un texto de traducción especializada a otro de características similares a los de traducción general).

La novena y última dificultad es la consecución de la coherencia argumentativa propia de los textos científicos, manteniendo las propiedades de univocidad y monorreferencialidad de los términos.

\section{CONCLUSIÓN}

En el caso de la traducción de términos de Patología y Parasitología de la Vid, como en el caso de cualquier otro tipo de traducción especializada, la labor previa del traductor es la documentación y la asimilación del conocimiento. Para ello, nada mejor que la creación y gestión de proyectos terminológicos que sirvan de apoyo para la estructuración conceptual del área de especialidad. La integración de la Terminología en la Traducción permitirá al traductor realizar correctamente el proceso traductológico, es decir, el análisis del texto original, su interpretación mental y la posterior construcción del texto final, o traducción propiamente dicha. Por este motivo, incluso las nuevas tecnologías apuestan firmemente por la creación de herramientas que integren las Memorias de Traducción y las herramientas de Gestión de Terminología en un único producto, como es el caso de la última generación de programas de Traducción Asistida por Ordenador. 


\section{BIBLIOGRAFÍA}

CORPUS DE REFERENCIA:

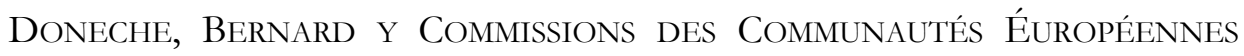
(1992): Les acquisitions récentes en microbiologie du vin: incidences sur les propriétés organoleptiques et les altérations du vin. París, Ed. Tec 8 Doc.

Martínez Robledo, Ma Isabel et Al. (1998): Patología y Parasitología de la Vid. Córdoba, Departamento de Bromatología y Tecnología de los Alimentos, Universidad de Córdoba.

SuÁrez Lepe, José Antonio e IÑigo Leal, Baldomero (1990): Microbiología lógica: fundamentos de unificación. Madrid, Ed. Mundi-Prensa.

Ough, C. S. (1996): Tratado básico de enología. Zaragoza, Ed. Acribia.

Bravo Abad, Francisco (1995): Del vino y otros temas. Madrid. Ed. Espasa.

CORPUS DE VACIADO:

Channet, M. y Reynier, A. (Traducción de F. Gil-Albert Velarde) (1974): Manual de Viticultura. Madrid, Ed. Mundi-Prensa.

Winkler, A. J. (TRAduCCión de Guillermo Fernández Lara) (1980): Viticultura (6 $6^{\mathrm{a}}$ Edición). México, Compañía Editorial Continental S. A. Hidalgo, Luis (1993): Tratado de Viticultura. Madrid, Ed. Mundi-Prensa. Brahnas, JeAn (1974): Viticulture. Montpellier, Imprimerie Paul Déhan. Galet, P. (1970): Précis de Viticulture. Montpellier, Imprimerie Paul Déhan. Universidad de Córdoba, Dpto. de Agronomía (1998): Apéndice. Nombres equivalentes de las enfermedades y alteraciones de la vid. Córdoba. 